\title{
Drivers of Regional Destination Competitiveness: A DEMATEL - Fuzzy TOPSIS Approach
}

\author{
Rio Benedicto Bire, Agustino Lukas Fischer Conterius and Asbi Nasar \\ State Polytechnic of Kupang, Indonesia
}

Received: $2020-10-05$ Accepted: 2021-04-19

Keywords:

Regional tourism; destination competitiveness; DEMATEL;

Fuzzy TOPSIS

Correspondent email: rio.bire@yahoo.com

\begin{abstract}
This paper aims to explore a conceptual criteria framework for measuring tourism destination competitiveness at the regional level to fill the existing gap in literature. This study was conducted in the East Nusa Tenggara (NTT) Province of Indonesia, by developing a tailored set of criteria for measuring destination competitiveness specific for the regional backdrop through rigorous literature review and indepth interviews with tourism experts. Moreover, a hybrid MCDM approach combining DEMATEL and Fuzzy TOPSIS techniques was employed to analyze interrelationships and importance rankings of the developed measurement criteria. This research developed a six-factor and twenty-three indicator framework deemed relevant for assessing destination competitiveness at the regional level. The six factors comprise of destination attraction, general infrastructure, superstructure, destination management, price competitiveness, and regional government policy. The DEMATEL analysis revealed regional government policy to be the most influential factor, whilst destination attraction was rendered the most important one. Results from the Fuzzy TOPSIS present the most important indicators from the framework as natural attraction, accessibility and port infrastructure, accommodation, the image of the destination, and priority towards the tourism sector. Findings from this research provide valuable insights in terms of proposing tourism policymakers with a blueprint of regional destination competitiveness criteria that offers critical inputs for developing medium and long-term tourism strategies.
\end{abstract}

2021 by the authors. Licensee Indonesian Journal of Geography Indonesi.

This article is an open access article distributed under the terms ind conditions of the Creative Commons

Attribution(CC BY NC) licensehttps://creativecommons.org/licenses/by-nc/4.0/.

\section{Introduction}

Tourism is regarded as one of the world's most rapidly growing industries (Nilashi, Yadegaridehkordi, \& Ibrahim, 2019). Realized as instrumental to economic development (Cucculelli \& Gof, 2015), many countries have positioned tourism as a priority sector within strategic economic plans. Consequently, development in tourism is apparent, especially among developing countries. Tourism development is heavily influenced by destination competitiveness which plays a key role in tourism marketing (Paula, Lopes, Muñoz, \& Alarcónurbistondo, 2018). Dwyer (2003) argues that the success of destinations is defined by its competitiveness relative to other destinations. Moreover, Leung \& Baloglu (2013) remarks that competitiveness is critical for destinations to gain an advantageous position in the continually changing world market, and long-term economic prosperity may be realized as tourism is enhanced in destinations. Accordingly, measuring destination competitiveness is viewed as quintessential for tourism development.

Destination competitiveness is commonly referred to as the ability of a region to outperform other destinations by virtue of excelling in delivering goods and services (Dwyer \& Kim, 2003). There are several renowned destination competitiveness models comprising a set of indicators that have been widely recognized in the tourism literature. Ritchie and Crouch (2003) developed the Calgary Model, stretching
36 attributes over 5 layers which are core resources and attractors, supporting factors and resources, destination management, qualifying and amplifying determinants, and destination policy, planning and development. Their model is considered as one of the most comprehensive ones in the tourism literature as it recognizes macro and micro economic factors (Azzopardi \& Nash, 2018; Caber, Albayrak, \& Matzler, 2012). Heath (2003) established a destination competitive framework in form of a house building model that consists of the foundation, building blocks, cement, and the roof. Heath's model is influenced by that of Ritchie and Crouch (2003), and provided an extension through its emphasis on human resource development, communication, and information management. Dwyer and Kim (2003) composed an integrated model that comprises of 7 main drivers which are endowed resources, created resources, supporting factors and resources, destination management, demand conditions, situational conditions, and global macro environment. Their model managed to incorporate the demand side of competitiveness as an explicit driver compared to the implicit rendition in those previously mentioned.

Perhaps the recent most applicable framework to measure tourism competitiveness is that structured by WEF (2019) in the Travel and Tourism Competitiveness Index (TTCI). The 
framework measures competitiveness at country level through four sub-indexes which are enabling environment, tourism and travel policy and enabling conditions, infrastructure, and natural and cultural resources. The four sub-indexes are then divided into 14 pillars. Nonetheless, the aforementioned models are considered robust for application at the national level, evident from the number of studies adopting them. Other noteworthy frameworks include that of Enright \& Newton (2004) who built upon the Calgary model and notably Porter's "diamond of national competitiveness" to formulate a model for Asia Pacific countries which is categorized into attractors and business-related factors. Moreover, Cvelbar et al. (2015) drew upon the foundations of Ritchie and Crouch, Dwyer and Kim, and TTCI to narrow down and categorize criteria into six factors which are macro -environment, general infrastructure, business environment, endowed resources, tourism infrastructure, and destination management. The study went further to evaluate destination competitiveness on national scales.

Similarly, the majority of empirical studies assessing destination competitiveness are also found at the country level (Enright \& Newton, 2004; Kneževi et al., 2015; Webster \& Ivanov, 2014). Nonetheless, a few studies have attempted evaluations at the regional level (Caber et al., 2012; Sánchez \& López, 2015; Zhang, Gu, Gu, \& Zhang, 2011; Zhou, Maumbe, Deng, \& Selin, 2015) by drawing from the models prevalent at the national scale by assuming that such frameworks can be applied into the specific context. However, a prominent concern is an empirical applicability as there is no "one size fits all" model for measuring any destination competitiveness (Enright \& Newton, 2004). Distinct geographical, historical, social, and political backgrounds may render a solid competitive model to be inapplicable to specific settings. Paula et al. (2018) argue that as there is competition among regional destinations, they require a more relevant approach in terms of measurement criteria and methodology, one which is found to be very limited in the literature. Consequently, they contend that renowned frameworks in the literature require "alterations" if were to be relevant for the regional layers. In doing so, the authors tailored TTCI to fit into regional assessment in Portugal and argued that Pillars 6 and 7 of TTCI (Prioritization of Travel \& Tourism and International Openness, respectively) did not make sense for assessing competitiveness in the specific backdrop.

Existing literature suggests the call for more empirical studies upon different contexts to develop suitable indicators for measuring destination competitiveness (Azzopardi \& Nash, 2018), signifying the gap for exploratory studies related to the subject. Previous works including Paula et al. (2018), Caber et al. (2012), Sanchez \& Lopez (2015), Zhang et al. (2011), and Zhou et al. (2015) further specify the call for relevant frameworks into assessing the regional backdrop. Moreover, to the best of our knowledge, there are yet studies to explore suitable frameworks for measuring destination competitiveness in developing countries that meets the specific regional context. Accordingly, this study sets to proposes an appropriate foundation for measuring contextual regional destination competitiveness by setting an initial blueprint from the previous prominent models which comprise a set of measurable factors along with a series of indicators pertaining to those factors.

This study is carried out in the East Nusa Tenggara (NTT) Province of Indonesia, a growing powerhouse of tourism in the country. Recently labeled as the "New Bali" by the national government, NTT recorded a growth of tourist visits as fourfold during 2014-2018 (BPS Nusa Tenggara Timur, 2019). Concerning Indonesia as a country, tourism is recognized as the third-largest contributor to national income (Bire, 2020; Yusuf, 2020). Nonetheless, NTT's provincial government has placed tourism to be the backbone for regional development, which is in accordance with the national government's priority towards tourism as the leading sector for national development (Kementrian Pariwisata Indonesia, 2019). Efforts in enhancing tourism are therefore imperative, which is amplified through tourism development at the regional level (Chaabouni, 2019; Soebagyo, 2012). The success of regional destinations is influenced by their competitiveness which requires a tailored, relevant model of measurement criteria.

In examining a conceptual criteria framework, we present the application of two multi-criteria decision making (MCDM) techniques, namely Decision Making Trial and Evaluation Laboratory (DEMATEL) and Fuzzy Technique for Order of Preference by Similarity to Ideal Solution (Fuzzy TOPSIS). The accuracy of the hybrid technique has been proven across various study disciplines, despite being relatively new to the tourism literature. The only previous application of the technique in tourism-related literature was found in Nilashi et al. (2018), which is proven to be a powerful tool for examining cause and effect relationships, as well as finding relative importance among criteria.

Drawing from what has been laid out above, the aim of this research is: (i) to develop a contextual relevant framework towards measuring destination competitiveness at the regional level, and (ii) to apply a hybrid MCDM technique combining DEMATEL and Fuzzy TOPSIS to reveal interrelationships and priority rankings of the measurement criteria. Accordingly, the results of this study are to provide regional tourism decision-makers with valuable insights towards medium and long-term strategies in regards to tourism competitiveness assessment and positioning.

\section{Methods}

In general, this research comprises 2 main stages which are (1) developing the regional tourism destination competitiveness framework that consists a set of factors along with a series of indicators, and (2) measuring interrelationships of the factors and priority rankings of the indicators. An initial set of regional destination competitiveness criteria was primarily derived from the Travel and Tourism Competitiveness Index (TTCI) developed by the World Economic Forum (WEF) (2019), Ritchie and Crouch (2003), Dwyer and Kim (2003), and Heath (2003). The model was then justified through in-depth interviews with 8 experts related to the field of regional tourism in Nusa Tenggara Timur (NTT) Province. These experts consisted of the Head and Secretary of the Tourism Office of NTT Province, one University Professor, the Head of the Tourism Department of the State Polytechnic, three experienced managers of tour operators, and one senior local tour guide. All experts had at least 5 years of experience related to regional tourism. The competitiveness factors and set of indicators were drawn based on relevancy to measure regional destination competitiveness in the context of Indonesia especially in NTT. Initially, these parameters were 
synthesized by listing all available and relevant ones from previous literature by drawing common themes. This initial set was then justified through exploratory in-depth interviews. Content analysis aided through the process of substantiating each factor and indicator.

Subsequent to the framework development is the analysis of interrelationships of competitiveness factors and importance levels of its indicators through a survey upon 40 experts including the previous 8 , which was extended to include experienced tourism office personnel, experienced regional travelers, tour operator managers, and university lecturers in the tourism field. This stage is done by applying a hybrid MCDM technique combining DEMATEL and Fuzzy TOPSIS. The advantages of the technique include the design of a tangible structured model revealing interrelationships between criteria and the accommodation of subjective judgments through the use of fuzzy numbers. The DEMATEL - Fuzzy TOPSIS method is explained in the following.

\section{DEMATEL}

DEMATEL is an effective technique used for analyzing the cause and effect relationship among components of a system, which transforms the causal relationships between the factors into a structural model. DEMATEL acts on a directional graph that displays directional relationships between factors (of the competitiveness framework), and defining the factors into two cause and effect groups. DEMATEL is conducted through the following steps:

Step 1. Gather experts' opinion and form a direct relations matrix. The scale of influence ranges from 0 (no influence) to 4 (very high influence). An $\mathrm{X}^{\mathrm{k}}=\left[\mathrm{X}_{\mathrm{ij}}{ }^{\mathrm{k}}\right]_{\mathrm{nxm}}$ matrix is formed to construct a direct relations matrix. All elements of $\mathrm{a}^{\mathrm{ij}}$ in main diameter of $\mathrm{X}^{\mathrm{k}}$ are 0 . The following formula is used to for a combined matrix:

$$
A=\left[A_{i j}\right]_{n x n}=\frac{1}{H} \sum_{k=1}^{H}\left[X_{i j}^{k}\right]_{n x n}
$$

Step 2. Construct a normalized primary direct matrix, which is called the initialinfluence matrix, D. The following formulas are used:

$$
\begin{aligned}
\mathrm{D} & =\frac{\mathrm{A}}{\mathrm{S}} \\
\mathrm{S} & =\max \left(\max \sum_{j=1}^{n} a_{i j}, \max \sum_{i=1}^{n} a_{i j}\right)
\end{aligned}
$$

Step 3. Compute the direct/indirect influence matrix. $\mathrm{L}$ is an identity matrix. The total relation matrix $\mathrm{T}$ is calculated by: $\mathrm{T}=\mathrm{D}(\mathrm{L}-\mathrm{D})^{-1}$

Step 4. Calculate $\mathrm{C}$ and $\mathrm{R}$ matrices, which are constructed to form $\mathrm{R}+\mathrm{C}$ (total effects given and received by a factor), and $\mathrm{R}-\mathrm{C}$ (the net effects that a factor contributes to the system). If $\mathrm{R}-\mathrm{C}$ is positive, the factor is net cause, otherwise, it is the net receiver.

\section{Fuzzy TOPSIS}

Fuzzy TOPSIS is employed in this study to assess the importance of indicators for each competitiveness driving factor. Indicators are the characteristics belonging to specific factors within the framework developed in stage one. Linguistic variables from experts' opinion are translated into fuzzy numbers for the TOPSIS scales for the importance weight of each indicator, and is are presented in Table 1.

Table 1. TOPSIS Scales

\begin{tabular}{ll}
\hline Linguistic Variable & Fuzzy Number \\
\hline Very Low (VL) & $(0,0.05,0.15)$ \\
Low $(\mathrm{L})$ & $(0.1,0.2,0.3)$ \\
Medium Low (ML) & $(0.2,0.35,0.5)$ \\
Medium (M) & $(0.3,0.5,0.7)$ \\
Medium High (MH) & $(0.5,0.65,0.8)$ \\
High (H) & $(0.7,0.8,0.9)$ \\
Very High $(\mathrm{VH})$ & $(0.85,0.95,1)$ \\
\hline
\end{tabular}

The fuzzy TOPSIS is done for $k$ decision-makers $\mathrm{D}_{\mathrm{r}}(\mathrm{r}=1$, . $., \mathrm{k})$ and a decision-making problem of $m$ criteria and $n$ alternatives $\mathrm{A}_{\mathrm{i}}(\mathrm{i}=1, \ldots, \mathrm{n})$, through the following steps:

Step 1. Aggregate the weights of criteria and ratings of alternatives through the equations:

$$
\begin{aligned}
& \widetilde{w}_{j}=\frac{1}{k}\left[\tilde{w}_{j}^{-1}+\widetilde{w}_{j}^{-2}+\ldots+\tilde{w}_{j}^{-k}\right] \\
& \tilde{x}_{i j}=\frac{1}{k}\left[\tilde{x}_{i j}^{-1}+\tilde{x}_{i j}^{-2}+\ldots+\tilde{x}_{j}^{-k}\right]
\end{aligned}
$$

where the weight of the $j^{\text {th }}$ criterion $(C j)$ is expressed by $\mathrm{W}_{\mathrm{r}^{-j}}$

Step 2. Construct fuzzy decision matrices of the criteria and alternative $D^{-}$through the following equations:

$$
\begin{gathered}
\left.\mathbf{W}^{\sim}=\overline{[} W_{1}^{\sim}+\mathbf{W}_{2}^{\sim}+\ldots+\mathbf{W}_{\mathrm{n}}^{\sim}\right] \\
D^{\sim}=\begin{array}{cccc}
a_{i} \\
a_{j} \\
a_{n}
\end{array}\left[\begin{array}{cccc}
X_{11}^{\sim} & X_{12}^{\sim} & X_{1 j}^{\sim} & X_{1 m}^{\sim} \\
\vdots & \vdots & \vdots & \vdots \\
X_{n 1}^{\sim} & X_{n 2}^{\sim} & X_{n j}^{\sim} & X_{n m}^{\sim}
\end{array}\right]
\end{gathered}
$$

Step 3. Construct a normalized fuzzy decision matrix, through the following equations:

$$
\begin{gathered}
R^{\sim}=\left[r_{i j}^{\sim}\right]_{n x m} \\
\mathrm{r}_{\mathrm{ij}}^{\sim}=\left(\frac{\mathrm{I}_{\mathrm{ij}}}{\mathrm{U}_{\mathrm{ij}}^{\sim}}, \frac{\mathrm{M}_{\mathrm{ij}}}{\mathrm{U}_{\mathrm{ij}}^{\sim}}, \frac{\mathrm{U}_{\mathrm{ij}}}{\mathrm{U}_{\mathrm{ij}}}\right), \text { and } \mathrm{u}_{\mathrm{j}}^{+}=\max \mathrm{U}_{\mathrm{ij}} \text { (benefit criteria) }
\end{gathered}
$$

$r_{i j}^{\prime \prime}=\left(\frac{L_{i j}}{U_{i j}^{-}}, \frac{M_{i j}}{M_{i j}}, \frac{L_{i j}}{L_{i j}}\right)$, and $L_{j}^{+}=\max L_{i j}($ cost criteria)

Step 4. Construct a weighted normalized decision matrix, $\tilde{R}$ $V^{\sim}$ through the following equation:

$V^{\sim}=\left[V_{i j}^{\sim}\right]_{n x m}, V_{i j}^{\sim}=X_{i j}^{\sim} x W_{i j}^{\sim}$

Step 5. Complete the Fuzzy Negative Ideal Solution, $A^{-}$and the Fuzzy Positive Ideal Solution, $\mathrm{A}^{+}$, through the following equations:

$A^{+}=\left\{V_{1}^{\sim+}, V_{j}^{\sim+}, \ldots, V_{m}^{\sim+}\right\}$ 


$$
A^{*}=\left\{V_{1}^{\sim}, V_{j}^{\infty}, \ldots, V_{m}^{\infty}\right\}
$$

where $\mathrm{V}_{\mathbf{j}}^{\sim+}=(1,1,1)$ and $\mathrm{V}_{\mathbf{j}}^{\sim-*}=(0,0,0)$

Step 6. Compute the distances indicated by each alternative from $\mathrm{V}_{\mathrm{j}}^{\sim+}$ to $\mathrm{V}_{\mathrm{j}}^{\sim-}$ using the following equations:

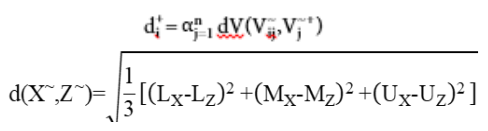

Step 7. Compute the closeness coefficient, $\mathrm{CC}_{\mathrm{i}}$ through the following equation:

$$
\mathrm{CC}_{\mathrm{i}}=\frac{\mathrm{d}_{\mathrm{i}}^{-}}{\mathrm{d}_{\mathrm{i}}^{+}+\mathrm{d}_{\mathrm{i}}^{-}}
$$

Step 8. Compute ranks of alternatives based on $\mathrm{CC}_{\mathrm{I}}$ in a decreasing order.

The research method steps are depicted in Figure 1.

\section{Result and Discussion}

Developing the Regional Destination Competitiveness Framework

The framework of regional destination competitiveness criteria is presented in Figure 2. Through a rigorous review of the literature and in-depth interviews with experts, six factors along with its set of indicators were derived to be appropriate for the regional level as:

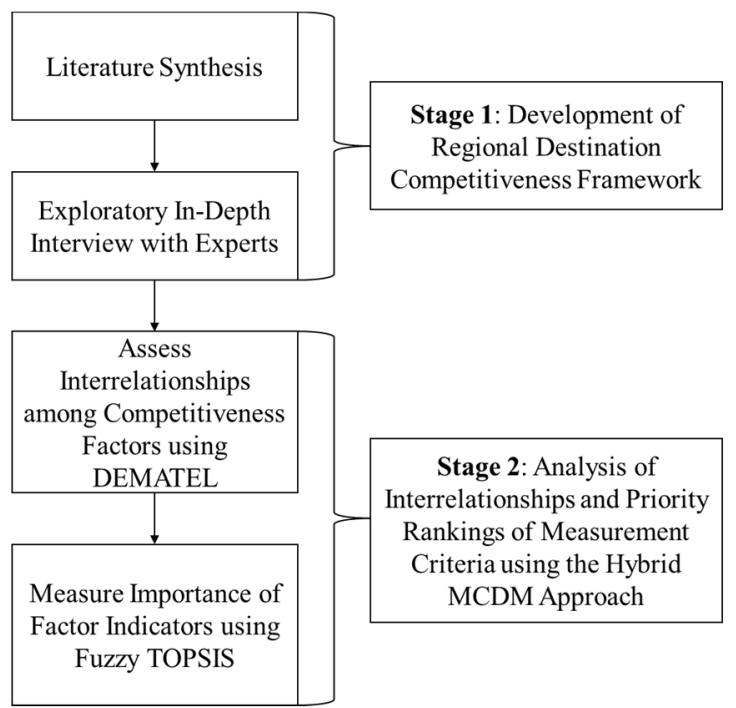

Figure 1. Research Method Steps

(1) Destination Attraction, which is generally agreed to be the primary appeal for a destination visit. This construct is consistent with that found in TTCI by WEF (2019), Ritchie \& Crouch (2003), Dwyer \& Kim (2003), and Heath (2003). The breakdown of attractions into natural and cultural ones is a common theme in theory and was validated from experts' opinions, despite there was contention for including man-made attraction to be an indicator of its own. The purposefully built attraction is evidently being pushed for development in the majority of regions across Indonesia, yet ended up being diluted as such category is more present and logical in larger cities only. Accordingly, the man-made part is embedded into the cultural category.

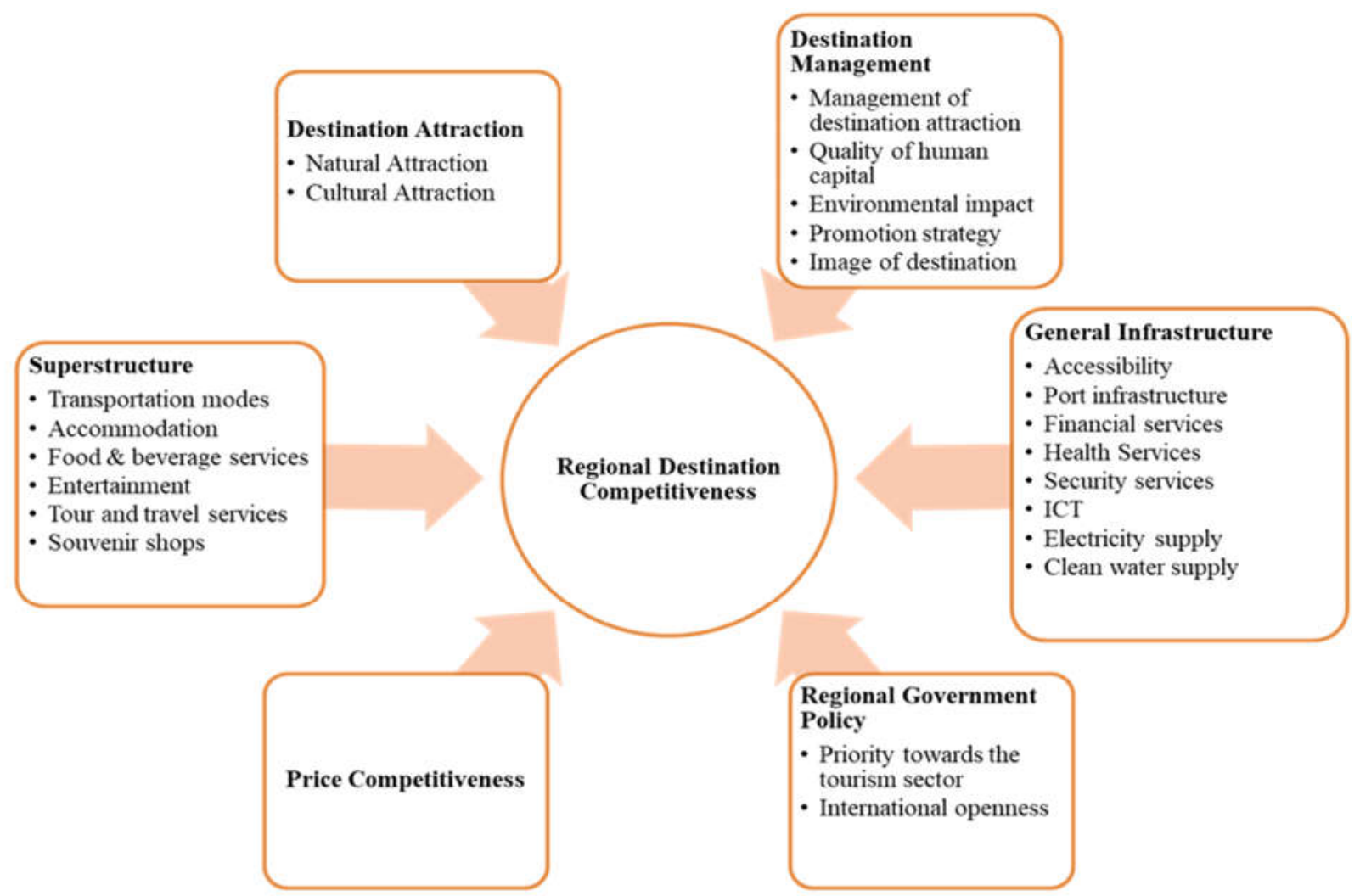

Figure 2. The Framework of Regional Destination Competitiveness 
Table 2. Final Result of DEMATEL Analysis

\begin{tabular}{lcccc}
\hline Factors & $\mathrm{Ri}$ & $\mathrm{Ci}$ & $\mathrm{Ri}+\mathrm{Ci}$ & 31.0869 \\
\hline Attraction & 15.4704 & 15.6166 & 29.0743 & -0.1462 \\
Infrastructure & 14.4197 & 14.6545 & 30.0292 & -0.2348 \\
Superstructure & 14.9634 & 15.0658 & 30.1279 & -0.1024 \\
Management & 14.9905 & 15.1374 & 29.9068 & -0.1469 \\
Policy & 15.8303 & 14.0766 & 29.5903 & 1.7537 \\
Price & 14.2334 & 15.3569 & & -1.1235 \\
\hline
\end{tabular}

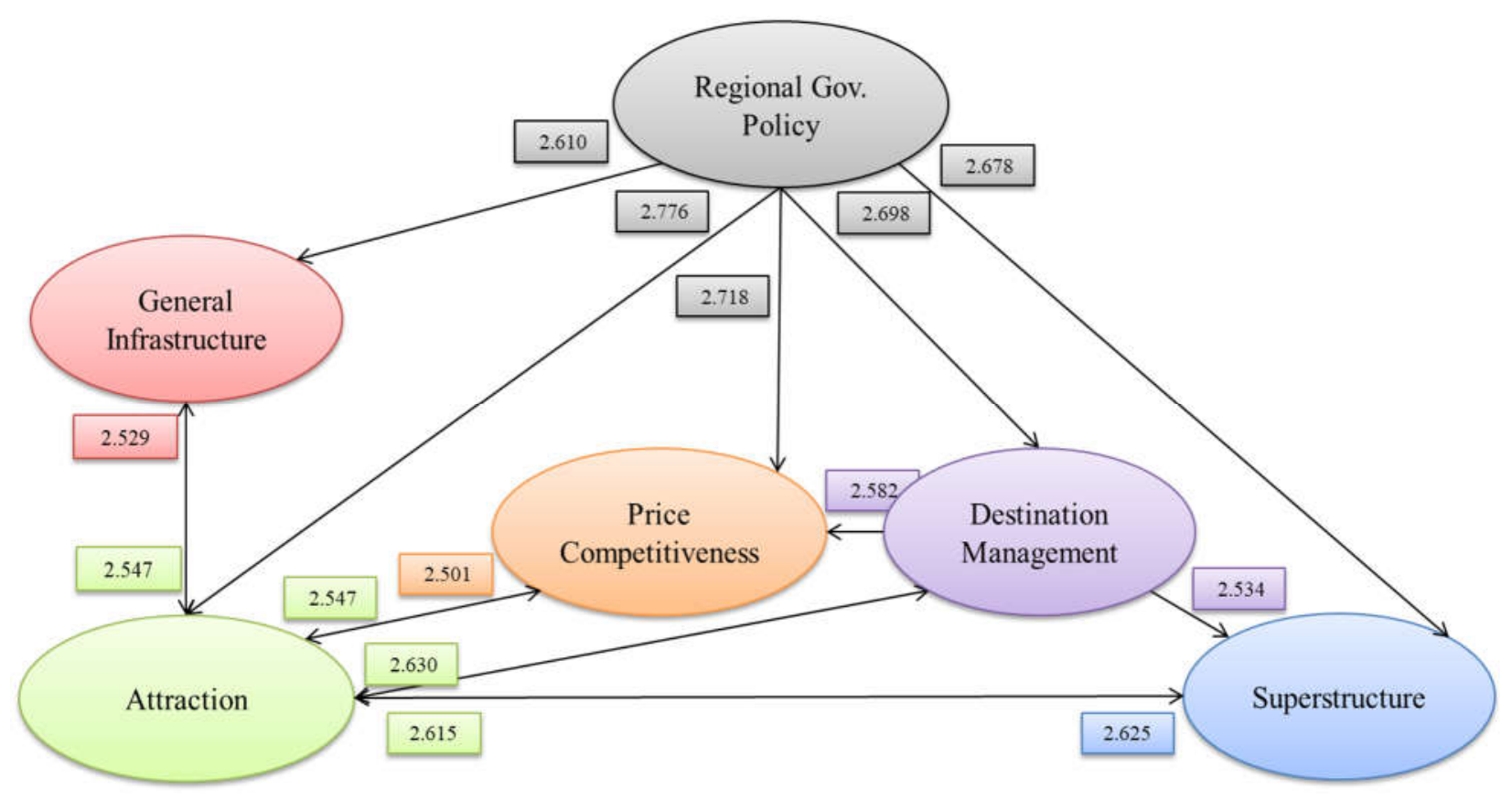

Figure 3. Interrelationships between Regional Destination Competitiveness Factors

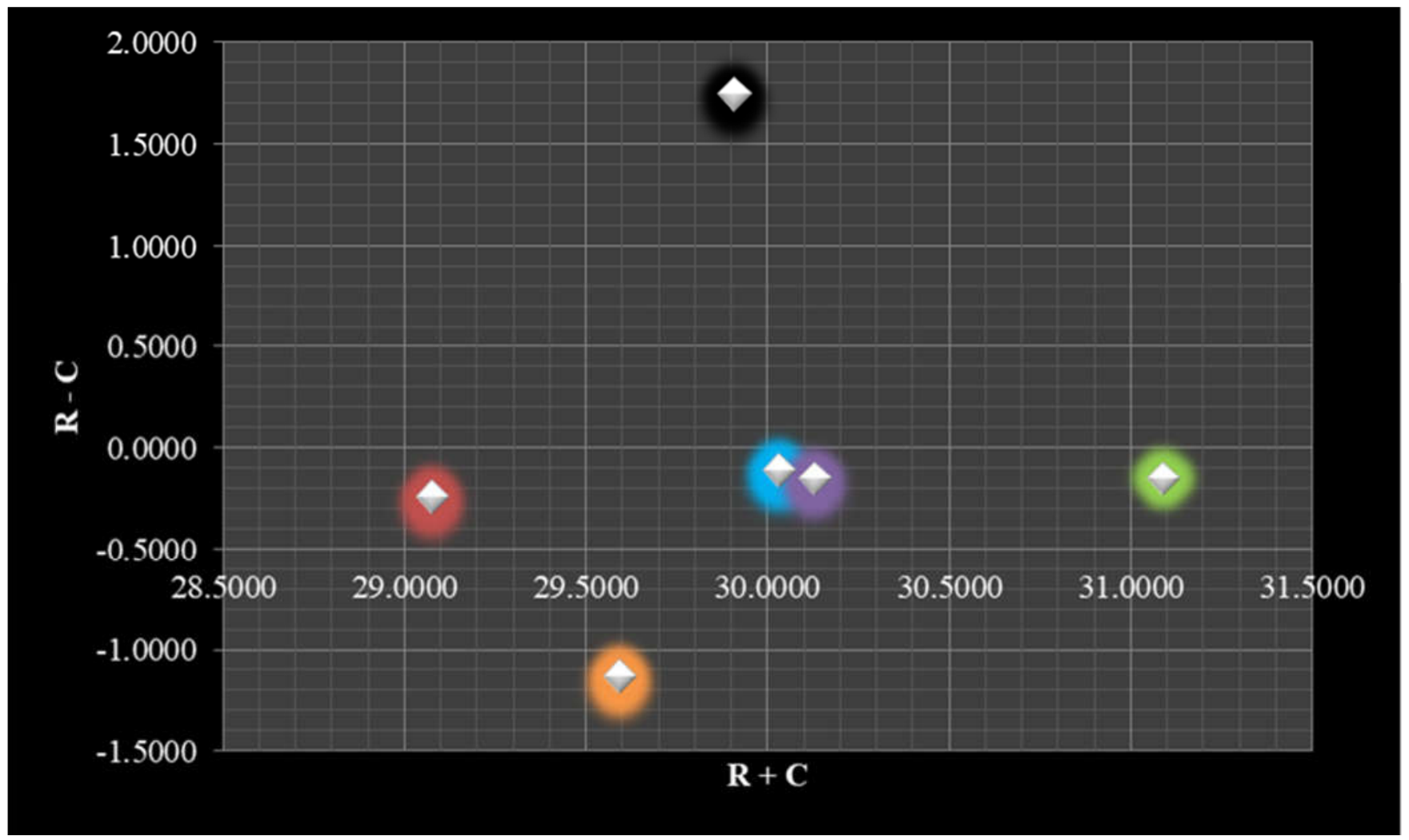

Figure 4. Causal Diagram of the Six Factors 
Table 5. Result of Fuzzy TOPSIS Analysis

\begin{tabular}{|c|c|c|c|c|c|}
\hline Factors & Indicators & FPIS & FNIS & $\mathrm{Cci}$ & Rank \\
\hline Destination & Natural attraction & 0.000 & 0.619 & 1.000 & 1 \\
\hline Attraction & Cultural attraction & 0.619 & 0.000 & 0.000 & 2 \\
\hline General & Accessibility & 0.000 & 1.220 & 1.000 & 1 \\
\hline \multirow[t]{7}{*}{ Infrastructure } & Port Infrastructure & 0.000 & 1.220 & 1.000 & 1 \\
\hline & Financial service & 0.704 & 0.000 & 0.000 & 7 \\
\hline & Health service & 0.341 & 0.630 & 0.649 & 6 \\
\hline & Security service & 0.315 & 0.710 & 0.693 & 4 \\
\hline & Information and communication technology (ICT) & 0.307 & 0.765 & 0.713 & 2 \\
\hline & Electricity supply & 0.324 & 0.676 & 0.676 & 5 \\
\hline & Clean water supply & 0.309 & 0.746 & 0.707 & 3 \\
\hline \multirow[t]{6}{*}{ Superstructure } & Transportation modes & 0.167 & 0.319 & 0.657 & 3 \\
\hline & Accommodation & 0.000 & 0.400 & 1.000 & 1 \\
\hline & Food \& beverage service & 0.061 & 0.364 & 0.857 & 2 \\
\hline & Entertainment & 0.300 & 0.153 & 0.338 & 4 \\
\hline & Tour \& travel service & 0.400 & 0.000 & 0.000 & 6 \\
\hline & Souvenir shops & 0.313 & 0.154 & 0.330 & 5 \\
\hline Destination & Management of destination attraction & 0.619 & 0.154 & 0.199 & 3 \\
\hline \multirow[t]{4}{*}{ Management } & Environmental impact & 0.614 & 0.156 & 0.203 & 2 \\
\hline & Quality of human capital & 0.459 & 0.061 & 0.117 & 4 \\
\hline & Promotion strategy & 0.465 & 0.000 & 0.000 & 5 \\
\hline & Image of destination & 0.000 & 0.465 & 1.000 & 1 \\
\hline Reg. Gov. & Priority towards the tourism sector & 0.000 & 0.215 & 1.000 & 1 \\
\hline Policy & International openness & 0.215 & 0.000 & 0.000 & 2 \\
\hline
\end{tabular}

(2) General Infrastructure, which refers to general facilities built to support human activities. This factor is proposed in TTCI by WEF (2019) as a sub-index of its own as part of the 4 criteria framework. Similarly, Ritchie \& Crouch (2003), Dwyer \& Kim (2003), and Heath (2003) considered infrastructure to be that of a supporting resource in terms of a competitiveness driver. All experts strongly confirm the inclusion of this factor which also is in line with the Indonesian Government's strategic planning regarding tourism development that emphasizes on infrastructure initiatives (Kementrian Pariwisata Indonesia, 2019). The breakdown of general infrastructure is accessibility, port infrastructure, financial services, health services, security services, information and communication technology (ICT), electricity supply, and clean water supply.

Accessibility is widely presented in the literature and was highlighted by the experts who agree that such construct significantly influences tourist experiences in terms of how quickly visitors may reach a particular destination. Port infrastructure, despite only explicitly presented in TTCI by WEF (2019), is highly regarded by the experts, especially those of government officials who consider it fitting for the geographical landscape of the islands-based regions in NTT and Indonesia in general. Financial services were put forward particularly by the managers of tour operators, suggesting that it highlights for tourists to feel assured. Health and security services are commonly presented in previous studies and are agreed upon by experts as a basic requirement for the wellbeing of tourists. ICT is proposed in previous literature partially for the information aspect but is specifically highlighted in TTCI. This indicator is highly regarded by practitioners, reasoning that it supports for seamless tour and travel services. Lastly, electricity supply and clean water were explicitly proposed as pillars in the TTCI model and were highly recommended by our experts considering that there are regions that despite natural attraction potential, fall short in terms of provision for the aforementioned, thus negatively affecting the whole tourism experience.

(3) Superstructure, which refers to facilities primarily serving the needs of tourism, is proposed explicitly in TTCI, Ritchie \& Crouch (2003), Dwyer \& Kim (2003), and Heath (2003). Transportation modes, accommodation, food and beverage services, entertainment, and tour and travel services, are widely referred to in tourism literature as proponents to support destination competitiveness and were validated by the experts to fit as indicators for the superstructure factor. Shopping was put forward specifically in Dwyer \& Kim (2003), and is widely used in literature as an indicator to assess destination performances. Our experts, however, strongly propose souvenir shops to be a more appropriate indicator into the regional context rather than shopping in general terms, which was contended to be more suitable for the national scale or that of urban areas.

(4) Destination Management, which refers to the process of planning, organizing, and controlling of the destination, is presented in all previous models. Attraction management is firmly acknowledged by the practitioners as an indicator that 
should encapsulate integrated administration, which is currently viewed as prone to various issues such as managerial overlaps. The criteria of quality of human capital, environmental impact, promotion strategy, and image of destination are widely addressed in all previous models and were drawn from subject matter remarks by the experts.

(5) Price Competitiveness, which refers to all general prices within a particular destination, is a common theme presented in TTCI, Ritchie \& Crouch (2003), Dwyer \& Kim (2003), and Heath (2003). Government experts, in particular, addressed price competitiveness to be a strong influence affecting tourist perceptions and decisions. They further addressed a current phenomenon of imbalances in setting tourism product prices among destinations in regional tourism.

(6) Regional Government Policy, which refers to the set of rules or principles set by the City or District government. All previous models present policies concerning tourism to be a criterion of destination competitiveness and were justified by the experts into regional government policy. Government official experts remark that the autonomous government system in Indonesia administers regional policymakers to adjust their system of laws, regulatory measures, courses of action, and funding priorities, including those related to the tourism sector. Accordingly, the experts firmly advocate the measure to influence competition. Priority towards the tourism sector and international openness were drawn from TTCI by WEF (2019), and were confirmed upon by our experts.

Measuring Interrelationships and Priority Rankings of the Developed Framework

The DEMATEL method was employed to identify interrelationships among the six factors of regional destination competitiveness as seen in Figure 2. Values of R, $\mathrm{C}, \mathrm{R}+\mathrm{C}$, and $\mathrm{R}-\mathrm{C}$ were obtained from the Total Relation Matrix as the final result of the DEMATEL analysis and is presented in Table 2. The results serve as a basis for depicting a model which reveals the relationships among the 6 factors, which is shown in Figure 3. Based on a threshold value obtained from the average of values from the Total Relations Matrix, significant relationships are presented in the model through the pointed arrows and the $\mathrm{T}$ values for influence direction and rate. In Figure 3, it can be observed that regional government policy has a direct influence on all other individual factors, with the highest $\mathrm{T}$ value is as of 2.776 upon destination attraction. Furthermore, regional government policy is revealed to have no significant direct influence from the other factors. Destination attraction has a significant direct influence on general infrastructure, destination management, superstructure, and price competitiveness, with the highest $\mathrm{T}$ value $(2.630)$ is towards destination management. Moreover, destination management is subject to two significant direct influences on price competitiveness $(\mathrm{T}=2.582)$ and superstructure $(\mathrm{T}=$ 2.534). Only one significant direct influence was identified for the superstructure, price competitiveness, and general infrastructure (all towards destination attraction) with $\mathrm{T}$ values of $2.626,2.501$, and 2.529 , respectively. The results in Table 2 can further produce a causal diagram that depicts the importance of factors as presented in Figure 4. Only regional government policy is rendered to be a net causer as its $R_{i}-C_{i}$ value was positive. All other factors are therefore set as net receivers due to producing negative values. The causing factor has an impact on the whole system, hence their performance can greatly influence the overall goal. Accordingly, it is generally accepted that the causer, in this case, regional government policy, should be paid more attention towards. Moreover, factors in the receiver or effect group are considered to be easily influenced. Additionally, results concerning $\mathrm{R}_{\mathrm{i}}+\mathrm{C}_{\mathrm{i}}$ reveal that destination attraction is the most important criterion of the set due to producing the highest value.

Following the DEMATEL analysis was the importance evaluation of factor indicators through the Fuzzy TOPSIS approach. As price competitiveness did not include a set of indicators, the criterion was excluded from the analysis. Linguistic judgments ranging from "very low" to "very high" obtained from the experts for each indicator were converted into fuzzy numbers for the TOPSIS analysis. Table 3 presents the results from the Fuzzy TOPSIS analysis, where rankings of indicators from each factor are displayed in column 6 .

\section{Discussion}

The framework and analysis of regional destination competitiveness criteria presented above provide critical insights on understanding what criteria influences and is most important to regional destination competitiveness. Accordingly, regional tourism stakeholders are presented to set focus on the most relevant criteria suitable for the regional backdrop. Our framework demonstrated distinction from previous models which were appropriate for a national setting. As distinct geographical, historical, social, and political backgrounds suggest a particular model to be inapplicable in other settings, our model contended that Pillars 6 and 7 of TTCI, which are priority towards the tourism sector and international openness, are indeed relevant for the regional level in Indonesia. This finding is contrary to that in Paula et al. (2018) who argued that the criteria were irrelevant for assessing regional tourism competitiveness. Moreover, instead of using the general shopping indicator found in prevalent frameworks such as Dwyer \& Kim (2003) and Enright \& Newton (2004), our regional model adjusted souvenir shops for the superstructure factor.

The DEMATEL analysis provided valuable understandings on interrelationships among the six factors set in the framework. It is discovered that regional government policy has direct and significant influences on all other factors, and is rendered to be the sole net causer. Accordingly, regional government policy has an impact on the whole tourism criteria. The significance of government policy in developing economies is also shown in Kubickova \& Li (2017), while the strong influence of public policies towards tourism growth is remarked by Hall \& Campos (2014). The most important factor, however, is destination attraction as it is subject to the highest relationship values with all other factors. This finding is in line with that found in Benito et al. (2014), Assaf \& Josiassen (2012), and Crouch (2011), who highly regard attractions to be the most important criteria of competition among destinations. Accordingly, this should provide insights for tourism stakeholders to enhance the packaging and marketing of attractions as a top priority.

Reports from the Fuzzy TOPSIS analysis identified natural attraction to be more important than cultural ones. 
This comes as no surprise for it is the common assertion by experts that the dominant pull factor for tourist visits is a natural attraction. This finding is also supported by Vangesayi (2003) who states that most destinations are dominated by natural attractions. With respect to the general infrastructure factor, both accessibility, and port infrastructure share status as the most important indicators. Enhancing for accessibility is considered by experts to be further be determined by the millage, traveling time, direct access, and alternative routes. With regards to port infrastructure, integrated terminal systems are a priority in the government's plans both regional and national in order to stimulate the effectiveness of traveling. Government experts highly contend of such considering the islands-based geographic conditions of NTT and Indonesia in general, which would really benefit from the development.

Unsurprisingly from the superstructure category, accommodation and food and beverage service tops the ranks as the first and second, respectively. The criticality of the two indicators for supporting tourism are also underlined in Manrai et al. (2018). In the context of developing nations, however, the development of the two should present efforts related to community-based tourism initiatives. As remarked in Chin et al. (2014), the involvement of local people in tourism will push for sustainability and regional economic development, and such efforts can be encouraged through government incentives for developing locally owned accommodation such as that of homestays. In accordance, "local taste" in food and beverages should push for more promotion. In the destination management category, the image of the destination is the most important enabler. Although determined by a variety of factors, the destination image is indeed largely influenced by its branding (Miličević, Mihalič, \& Sever, 2017). Unfortunately, branding in NTT and Indonesia, in general, has beard inconsistency throughout the last several years, although large amounts of investment have been allocated for such purposes. In contrast, the importance of consistency in image branding is underlined in Baker \& Cameron (2008).

Regional government policy as the sixth factor sees priority towards the tourism sector as more important than international openness. Indonesia administers an autonomous government system that allows for each province and city or district to adjust for their sectoral priorities. Such policy gives chance for regional decisionmakers to seize opportunities in regional economic development. This particular indicator is viewed as a strong foundation for enabling all other factors in our criteria framework. Accordingly, governments may channel funds to essential development projects, and coordinate upon necessary resources to push for development. International openness, on the other hand, can condition for relative advantage over other regions in terms of amplifying foreign investments and tourist visits. The previous is specifically addressed in Kovacevic et al. (2018), asserting that low foreign investments may be a serious shortcoming for tourism development in small destinations.

\section{Conclusion}

Existing tourism literature calls for exploratory studies to develop an understanding of the factors that affect tourism destination competitiveness. Diverse components make up destination competitiveness, and no set of criteria can be universally applicable to all contexts. This research carried out the agenda to fill in the gap of limited frameworks for assessing regional destination competitiveness. Firstly, we contributed in methodology enhancement by proposing a relative framework for regional destinations by modifying and adapting renowned models in the literature. We developed a six-factor and twenty-three indicator framework deemed relevant for the regional backdrop in Indonesia. This was done through rigorous literature reviews by synthesizing and drawing common themes, and subsequently by exploratory in-depth interviews with regional tourism experts in the NTT Province of Indonesia. Content analysis aided through the process of substantiating each factor and indicator. Our second contribution relates to providing insights on interrelationships and priority rankings of the competitiveness criteria by applying a hybrid MCDM approach through DEMATEL and Fuzzy-TOPSIS techniques. The results reveal regional government policy to be the most influential factor, whilst destination attraction was rendered the most important one. Moreover, the most important indicators from the framework are a natural attraction, accessibility and port infrastructure, accommodation, an image of the destination, and priority towards the tourism sector. This research is not without theoretical and methodological limitations. As the framework criteria in this study angle towards the supply side of competitiveness, future studies may also incorporate the demand side such as tourist preferences into the context. Furthermore, future researchers can go further and empirically test our model to assess destination competitiveness at the regional level, and may also apply criteria weights prior to empirical assessment, which can be done using other multi-criteria approaches such as Fuzzy AHP. Another recognized limitation in this study is the application of the hybrid MCDM which entails highly subjective data, which may limit reliability. Finally, results in this research should be contrasted with other destination settings in order to test the extent of what is being proposed here.

\section{References}

Assaf, A. G., \& Josiassen, A. (2012). Identifying and Ranking the Determinants of Tourism Performance: A Global Investigation. Journal of Travel Research. https:// doi.org/10.1177/0047287511426337

Azzopardi, E., \& Nash, R. (2018). A Review of Crouch and Ritchie's, Heath's, and Dwyer and Kim's Models of Tourism Competitiveness. 22, 247-254.

Baker, M. J., \& Cameron, E. (2008). Critical Success Factors in Destination Marketing. Tourism and Hospitality Research. https://doi.org/10.1057/thr.2008.9

Benito, B., Solana, J., \& López, P. (2014). Determinants of Spanish regions' tourism performance: A two-stage, double-bootstrap data envelopment analysis. Tourism Economics. https:// doi.org/10.5367/te.2013.0327

Bire, R. B. (2020). Efficiency Analysis of Hotels Listed in the Indonesian Stock Exchange Market. TOURISM: Jurnal Travel, Hospitality, Culture, Destination, and MICE, 3(01), 1-6. Retrieved from http://www.jurnal.pnk.ac.id/index.php/tourism/ article/view/656/265

BPS Nusa Tenggara Timur. (2019). Nusa Tenggara Timur Province in Figures 2019.

Caber, M., Albayrak, T., \& Matzler, K. (2012). Classification of the destination attributes in the content of competitiveness (by revised importance-performance analysis). Journal of Vacation 

Marketing,
$18(1)$
43-56.
https://

doi.org/10.1177/1356766711428802

Chaabouni, S. (2019). China's regional tourism e ffi ciency区: A two -stage double bootstrap data envelopment analysis. Journal of Destination Marketing \& Management, 11(September 2017), 183-191. https://doi.org/10.1016/j.jdmm.2017.09.002

Chin, C.-H., Lo, M.-C., Songan, P., \& Nair, V. (2014). Rural Tourism Destination Competitiveness: A Study on Annah Rais Longhouse Homestay, Sarawak. Procedia - Social and Behavioral Sciences. https://doi.org/10.1016/j.sbspro.2014.07.271

Crouch, G. I. (2011). Destination competitiveness: An analysis of determinant attributes. Journal of Travel Research. https:// doi.org/10.1177/0047287510362776

Cucculelli, M., \& Gof, G. (2015). Does sustainability enhance tourism destination competitiveness? Evidence from Italian Destinations of Excellence. https://doi.org/10.1016/ j.jclepro.2014.12.069

Drakulić Kovačević, N., Kovačević, L., Stankov, U., Dragićević, V., \& Miletić, A. (2018). Applying destination competitiveness model to strategic tourism development of small destinations: The case of South Banat district. Journal of Destination Marketing and Management. https://doi.org/10.1016/ j.jdmm.2017.01.002

Dwyer, L., \& Kim, C. (2003). Tourism Destination Competitiveness : Determinants and Indicators. Current Issues in Tourism, 6(5), 369-414. https:// doi.org/10.1080/13683500308667962

Enright, M. J., \& Newton, J. (2004). Tourism destination competitiveness : a quantitative approach. $25,777-788$. https:// doi.org/10.1016/j.tourman.2004.06.008

Hall, C. M., José, M., \& Campos, Z. (2014). Public Administration and Tourism - International and Nordic Perspectives Introduction to the special issue. Scandinavian Journal of HeathPublic Administration, 18(1), 3-7.

Heath, E. (2003). Towards a model to enhance destination competitiveness: a Southern African perspective. Journal of Hospitality and Tourism Management.

Hsu, T. K., Tsai, Y. F., \& Wu, H. H. (2009). The preference analysis for tourist choice of destination: A case study of Taiwan. Tourism Management. https://oi.org/10.1016/ j.tourman.2008.07.011

Kementrian Pariwisata Indonesia. (2019). Laporan akuntabilitas kinerja Kementrian Pariwisata 2018 [Performance accountability report of the Tourism Ministry of Indonesia 2018].

Kneževi, L., Dwyer, L., Koman, M., \& Mihali, T. (2015). Drivers of Destination Competitiveness in Tourism: A Global Investigation. Journal of Travel Research. https:// doi.org/10.1177/0047287515617299

Kubickova, M., \& Li, H. (2017). Tourism Competitiveness, Government and Tourism Area Life Cycle (TALC) Model: The Evaluation of Costa Rica, Guatemala and Honduras. International Journal of Tourism Research. https:// doi.org/10.1002/jtr.2105

Leung, X. I. Y. U., \& Baloglu, S. (2013). Tourism Competitiveness of Asia Pacific Destinations. 18, 371-384.

Manrai, L. A., Manrai, A. K., \& Friedeborn, S. (2018). Environmental determinants of destination competitiveness and its Tourism Attractions-Basics-Context, A-B-C, indicators. Journal of Economics, Finance and Administrative Science. https://doi.org/10.1108/jefas-01-2018-0010

Miličević, K., Mihalič, T., \& Sever, I. (2017). An Investigation of the Relationship Between Destination Branding and Destination Competitiveness. Journal of Travel and Tourism Marketing. https://doi.org/10.1080/10548408.2016.1156611

Mujiya Ulkhaq, M., Akshinta, P. Y., Nartadhi, R. L., \& Susatyo Nugroho, W. P. (2016). Assessing Sustainable Rural Community Tourism Using the AHP and TOPSIS Approaches under Fuzzy Environment. MATEC Web of Conferences. https://doi.org/10.1051/matecconf/20166809003

Nilashi, M., Ibrahim, O., Yadegaridehkordi, E., Samad, S., Akbari,
E., \& Alizadeh, A. (2018). Travelers decision making using online review in social network sites: A case on TripAdvisor. Journal of Computational Science. https://doi.org/10.1016/ j.jocs.2018.09.006

Nilashi, M., Yadegaridehkordi, E., \& Ibrahim, O. (2019). Analysis of Travellers ' Online Reviews in Social Networking Sites Using Fuzzy Logic Approach. International Journal of Fuzzy Systems. https://doi.org/10.1007/s40815-019-00630-0

Paula, A., Lopes, F., Muñoz, M. M., \& Alarcón-urbistondo, P. (2018). Annals of Tourism Research Regional tourism competitiveness using the PROMETHEE approach. Annals of Tourism Research, 73(June), 1-13. https://doi.org/10.1016/ j.annals.2018.07.003

Ritchie, J. R. B., \& Crouch, G. I. (2003). The competitive destination: a sustainable tourism perspective. In The competitive destination: a sustainable tourism perspective. https:// doi.org/10.1079/9780851996646.0000

Sánchez, A. G., \& López, D. S. (2015). Tourism destination competitiveness: The Spanish Mediterranean case. Tourism Economics, 21(6), 1235-1254. https://doi.org/10.5367/ te.2014.0405

Soebagyo, S. (2012). STRATEGI PENGEMBANGAN PARIWISATA. Liquidity, 1(2).

Vengesayi, S. (2003). a Conceptual Model of Tourism Destination Competitiveness and Attractiveness. Conceptual Papers / Marketing Theory Track.

Webster, C., \& Ivanov, S. (2014). Transforming competitiveness into economic bene fi ts: Does tourism stimulate economic growth in more competitive destinations? Tourism Management, 40, 137-140. https://doi.org/10.1016/ j.tourman.2013.06.003

WEF. (2019). The Travel \& Tourism Competitiveness Report 2019. Retrieved from http://www3.weforum.org/docs/ WEF_TTCR_2019.pdf

Yusuf, M. (2020). How far can tourism go? Residents' attitudes toward tourism development in Yogyakarta City, Indonesia. Indonesian Journal of Geography. https://doi.org/10.22146/ IJG.46148

Zhang, H., Gu, C. lin, Gu, L. wen, \& Zhang, Y. (2011). The evaluation of tourism destination competitiveness by TOPSIS \& information entropy - A case in the Yangtze River Delta of China. Tourism Management, 32(2), 443-451. https:// doi.org/10.1016/j.tourman.2010.02.007

Zhou, Y., Maumbe, K., Deng, J., \& Selin, S. W. (2015). Resourcebased destination competitiveness evaluation using a hybrid analytic hierarchy process (AHP): The case study of West Virginia. Tourism Management Perspectives, 15, 72-80. https:// doi.org/10.1016/j.tmp.2015.03.007 